\title{
Establishment of a Langerhans cell histiocytosis lesion cell line with dermal dendritic cell characteristics
}

\author{
ICHIRO MURAKAMI $^{1}$, JEAN GOGUSEV ${ }^{2}$, FRANCIS JAUBERT $^{3}$, MICHIKO MATSUSHITA $^{4}$, \\ KAZUHIKO HAYASHI $^{1}$, IKUO MIURA ${ }^{5}$, TAKEHIRO TANAKA ${ }^{6}$, TAKASHI OKA ${ }^{7}$ and TADASHI YOSHINO ${ }^{7}$ \\ ${ }^{1}$ Division of Molecular Pathology, Faculty of Medicine, Tottori University, Yonago, Tottori 683-8503, Japan; \\ ${ }^{2}$ Inserm U507 and U1016, Institut Cochin, 75014 Paris; ${ }^{3}$ University of Paris Descartes (Paris V), 75006 Paris, France; \\ ${ }^{4}$ Department of Pathobiological Science and Technology, School of Health Science, Faculty of Medicine, \\ Tottori University, Yonago 683-8503; ${ }^{5}$ Division of Hematology and Oncology, St. Marianna University School \\ of Medicine Hospital, Kawasaki, Kanagawa 216-8511; ${ }^{6}$ Department of Pathology, Okayama University Hospital, \\ Okayama 700-8530; ${ }^{7}$ Department of Pathology, Okayama University Graduate School of Medicine, \\ Dentistry and Pharmaceutical Sciences, Okayama 700-8530, Japan
}

Received July 7, 2014; Accepted October 2, 2014

DOI: $10.3892 /$ or.2014.3567

\begin{abstract}
A cell line named PRU-1, derived from a Langerhans cell (LC) histiocytosis (LCH) skull lesion of a 7-year-old boy, was established and characterized. PRU-1 is an adherent spindle-shaped cell line that shows no Birbeck granules on electron microscopy. Flow cytometric analysis of cells collected from the early seventh passage showed no LC phenotypes of CD1a and S100 protein. Immunostaining of PRU-1 cells also revealed no expression of LC markers but showed expression of CD11c, CD54 (ICAM-1) and CD68, which was also observed in some peripherally located cells of the original LCH lesion. The PRU-1 cells stained positive for factor XIIIa and negative for CD34, suggesting a dermal dendritic cell phenotype. Cytogenetic analyses revealed abnormalities such as 39,XY,-2,-4,-8,-12,-12,-14, add(18)(q21),20,+mar and $44, X Y,-11,-14$, add(18)(q21). TCR $\gamma$ rearrangement in the PRU-1 cells was not amplified by PCR. Tumorigenicity was not proven by xenografting into SCID mice. A conditioned medium from PRU-1 culture induced the proliferation of peripheral blood lymphocytes as well as the activation of monocytes from a healthy donor into CD1a-positive LC-like cells. Because the phenotypic characteristics of PRU-1 differed from those of CDla-positive abnormal LC-like cells ( $\mathrm{LCH}$ cells), it was likely that the PRU-1 cells were derived from peripherally located cells of the $\mathrm{LCH}$ lesion rather than $\mathrm{LCH}$ cells. $\mathrm{LCH}$ has been regarded as a type of granulomatous neoplasm with several
\end{abstract}

Correspondence to: Dr Ichiro Murakami, Division of Molecular Pathology, Faculty of Medicine, Tottori University, 86 Nishi-cho, Yonago, Tottori 683-8503, Japan

E-mail: ichiro.murakami.09@gmail.com

Key words: Langerhans cell histiocytosis, cell line, dermal dendritic cell intermingled inflammatory cells and influenced by stimuli such as Merkel cell polyomavirus (MCPyV) infection or cigarette smoking. However, in the PRU-1 cells, MCPyV-DNA was not detected by PCR. Stromal cell-like PRU-1 cells are likely to produce some growth or differentiation factors, which may play important roles in LCH lesion formation, cell maintenance and LC-like cell induction.

\section{Introduction}

Langerhans cell (LC) histiocytosis ( $\mathrm{LCH})$ is a disease characterized by the proliferation of CD1a-positive abnormal LC-like cells (LCH cells). The Writing Group of the Histiocyte Society has defined $\mathrm{LCH}$ as a single system disease or a multisystem disease (1). Although it has not yet determined whether LCH is a reactive or neoplastic disease, recent data suggest a reactive disorder with an underlying oncogenic potential. In this context, both LCH and pulmonary $\mathrm{LCH}$ harbor the $B R A F$ V600E mutation $(2,3)$ and appear to be related to stimuli such as viral infection (4-6) and cigarette smoking (7,8). In addition, it has been reported that the extinction of stimuli may cause spontaneous healing of the LCH disease (9-11).

In terms of $\mathrm{LCH}$ as a reactive disease, it has been suggested that viruses might act as causal candidates $(6,12-15)$. Scappaticci et al (16) found that peripheral blood lymphocytes from $\mathrm{LCH}$ patients contained chromatid and/or chromosomal breaks, as well as structural chromosomal rearrangements, and concluded that $\mathrm{LCH}$ is pathogenetically related to an inherent genetic instability or is caused by environmental viral agents. We recently described the possibility of a causal relationship between Merkel cell polyomavirus (MCPyV) and LCH (4).

Establishment of a cell line derived from an $\mathrm{LCH}$ lesion may provide significant information regarding the cell origin and pathogenesis of the disease. In a previous report, we described the establishment of a bone LCH lesion-derived cell line named DOR-1, which showed CD10-positive bone marrow stromal cell characteristics (17). In the present study, 
Table I. Immunohistochemical analyses of PRU-1, a new cell line derived from a bone LCH lesion.

\begin{tabular}{|c|c|c|c|c|}
\hline Antibodies against & Clones & Sources & Dilution & Immunoreactivity \\
\hline CD1a & SK9 & $\mathrm{BD}$ & $1: 20$ & - \\
\hline CD10 & $56 \mathrm{C} 6$ & Novocastra & $1: 50$ & - \\
\hline S100 & - & Dako Japan & $1: 1,000$ & - \\
\hline CD11c & 3.9 & YLEM & $1: 20$ & + \\
\hline CD14 & $\mathrm{M} \phi \mathrm{P} 9$ & BD Biosciences & $1: 20$ & - \\
\hline CD34 & QBEND-10 & Dako Japan & Diluted & - \\
\hline CD43 & MT1 & Euro-Diagnostica AB & $1: 20$ & + \\
\hline CD54 (ICAM-1) & BBIG-I1 & Seikagakukogyo & $1: 1,000$ & + \\
\hline CD56 (NCAM) & $123 \mathrm{C} 3$ & Monosan & $1: 20$ & + \\
\hline CD68 & KP-1 & Dako Japan & $1: 50$ & + \\
\hline CD99 (MIC2) & 19 & Sigma & $1: 40$ & + \\
\hline CD106 ( $\alpha$ VCAM-1) & BBIG-V1 & British Bio Technology & $1: 1,000$ & + \\
\hline CD141 (thrombomodulin) & 1009 & Dako Japan & $1: 25$ & + \\
\hline$\alpha \mathrm{SMA}$ & $1 \mathrm{~A} 4$ & Dako Japan & $1: 50$ & + \\
\hline Muscle actin & HHF35 & Enzo Diagnostics & $1: 50$ & + \\
\hline FXIIIa & - & Lab Vision Corporation & $10 \mu \mathrm{g} / \mathrm{ml}$ & + \\
\hline HLA-DR & DK22 & Dako Japan & $1: 20$ & - \\
\hline Keratin (AE1/3) & $\mathrm{AE} 1 / 3$ & Chemicon & $1: 500$ & + \\
\hline Vimentin & Vim3B4 & Dako Japan & $1: 50$ & + \\
\hline
\end{tabular}

LCH, Langerhans cell histiocytosis; $\alpha$ SMA, $\alpha$-smooth muscle actin. BD Biosciences, San Jose, CA, USA; Chemicon, Temecula, CA, USA; Dako Japan, Kyoto, Japan; Enzo Diagnostics, New York, NY, USA; Immunotech, Marseille, France; Lab Vision Corp., Fremont, CA, USA; Monosan, Uden, The Netherlands; Novocastra, Newcastle upon Tyne, UK; Seikagakukogyo, Tokyo, Japan; Sigma, St. Louis, MO, USA; YLEM, Roma, Italy; Euro Diagnostica AB, Malmö, Sweden.

we report a second cell line named PRU-1, established also from bone $\mathrm{LCH}$, which shows stromal dermal dendritic cell (DDC) characteristics.

\section{Materials and methods}

Patient. A lytic lesion developed in the skull of a 7-yearold boy who was biopsied at surgery. Histological analysis confirmed an LCH lesion, which was composed of $\mathrm{CD}^{+} \mathrm{a}^{+}$and $\mathrm{S} 100^{+}$cells that intermingled with inflammatory cells and were surrounded by dense mesenchymal tissue.

Cell culture. A written consent to use the biopsy material for laboratory purposes was obtained from the patient's parents. The cells were then allowed to attach to the culture flask and incubated at $37^{\circ} \mathrm{C}$ in Dulbecco's modified Eagle's medium (DMEM) supplemented with $10 \%$ fetal calf serum, L-glutamine and antibiotics (Invitrogen-Life Technologies, Cergy-Pontoise, France). After several days, spindle-shaped cells appeared, which were admixed with macrophage-like cells and lymphocytes. After 5-6 weeks of culture, a mixed cell population, including polygonal and spindle-shaped cells, developed. The culture, which was then named PRU-1, continued growth and proliferation and was passaged at a density of $2 \times 10^{5}$ cells $/ \mathrm{ml}$.

Flow cytometry. For two-color flow cytometry, PRU-1 cells $\left(2 \times 10^{5}\right)$ were detached from the culture flask and washed with PBS containing $0.5 \%$ bovine serum albumin, followed by incu- bation with specific antibodies. Non-specific immunolabeling was blocked by treating the cells with heat-inactivated rabbit serum (Sigma-Aldrich). Most of the monoclonal antibodies (mAbs) used were directly conjugated with phycoerythrin or fluorescein isothiocyanate. For the control, isotype-matched irrelevant $\mathrm{mAbs}$ at the same dilution as the specific antibodies were used. The stained cells were analyzed on a fluorescence activated cell sorter Calibur flow cytometer (BD Biosciences, San Jose, CA, USA), and data evaluation was performed using the CellQuest software (BD Biosciences).

Immunocytochemistry and special staining of PRU-1 cells. PRU-1 cells were analyzed by immunocytochemistry using the mAbs and polyclonal antibodies listed in Table I. Cytocentrifuge smears, which were prepared after the detachment of adherent PRU-1 cells growing on a culture chamber slide (Falcon; BD Labware, Franklin Lakes, NJ, USA), were fixed in cold acetone for $10 \mathrm{~min}$, rinsed in PBS and incubated with a primary antibody. The specific antibodies were revealed using a polymer-based immunoperoxidase technique (EnVision Plus; DakoCytomation, Glostrup, Denmark). PAS reaction and diastase PAS reaction were conducted.

DNA extraction and analysis of TCR $\gamma$ rearrangements in the primary LCH lesion and PRU-1 cells. Extraction of DNA from PRU-1 was performed using the proteinase $\mathrm{K}$ and phenol/ chloroform/isoamyl alcohol (25:24:1 v/v/v) standard procedure. The presence of TCR $\gamma$ rearrangement in the cells was investi- 

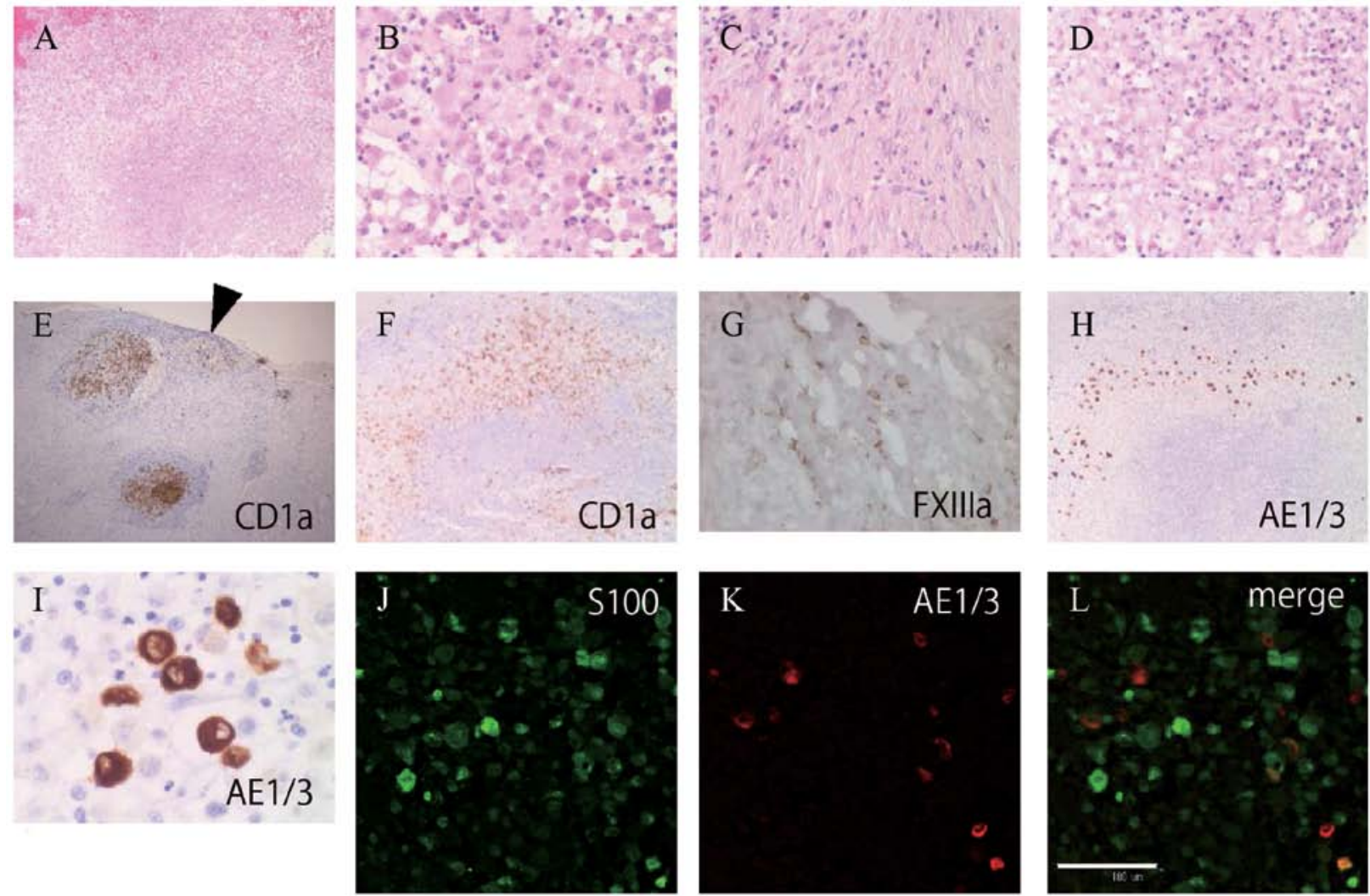

Figure 1. Histological and immunohistochemical analysis of the original LCH lesion including CD1a-positive abnormal Langerhans cell-like cells (LCH cells) with a zoning phenomenon. (A) Granulomatous lesion with central necrosis, hematoxylin and eosin (H\&E) stain (magnification, x4). (B) LCH cells with kidney-like nuclei and pale cytoplasm admixed with lymphocytes and eosinophils (H\&E, magnification, x20). (C) Peripheral part of the lesion showing a fibrosis-like pattern (H\&E, magnification, x20). (D) The central necrotic region of the nodular lesion (H\&E, magnification, x20). (E) Immunohistochemical analysis showed two large nodular clusters and a peripheral small cluster (arrowhead) of CD1a-positive LCH cells (magnification, x4). (F) CD1a-positive LCH cell-proliferated lesion contained a CD1a-negative central necrotic area (magnification, x4). (G) Factor XIIIa (FXIIIa)-positive cells scattered in the peripheral fibrous area (magnification, $\mathrm{x} 40$ ). (H and I) AE1/3-positive cells scattered in the middle area. $\mathrm{H}$ : same field of (A) (H, magnification, $\mathrm{x} 4$; I, magnification, $\mathrm{x} 40)$. (J-L) Double staining for S100 protein and AE1/3 in the same lesion. (J) S100 (magnification, x20). (K) AE1/3 (magnification, x20). (L) Merge (magnification, $\mathrm{x} 20$ ). $\mathrm{S} 100^{+} / \mathrm{AE} 1 / 3^{+}$cells (orange), $\mathrm{S} 100^{+} / \mathrm{AE} 1 / 3^{-}$cells (green), and S100-AE1/3+ cells (red) intermingled. White scale bar, $100 \mu \mathrm{m}$.

gated using PCR-amplified DNA from a paraffin-embedded, formalin-fixed original LCH lesion and the proliferating PRU-1 cells following the BIOMED-2 collaboration study protocol (18). PCR products were analyzed using GeneMapper ${ }^{\mathrm{TM}}$ software v.3.5 (Applied Biosystems, Foster City, CA, USA).

Electron microscopy (EM). Ultrastructural examination of PRU-1 was performed at different passages after fixation in glutaraldehyde following classical EM protocols of the Okayama University Central Laboratory (Okayama, Japan).

Cytogenetics. PRU-1 metaphases were analyzed according to standard methods of SRL, Inc. (Tachikawa, Tokyo, Japan).

Effects of a conditioned medium from PRU-1 cell culture supernatant on the biology and phenotype of lymphocytes and monocytes from a healthy donor. A conditioned medium was prepared using the supernatant of 1-week cultured PRU-1 cells and diluted with DMEM at a volume ratio of 1:1; this was then used to treat lymphocytes and/or monocytes isolated using a pore filter [0.4- $\mu \mathrm{m}$ pore filter (30-mm Millicell; Nihon Millipore, Tokyo, Japan)]. The conditioned medium from HeLa cell culture was used as the control.
Xenografting into SCID mice. Animal studies were approved by Okayama University Animal Research Laboratory. PRU-1

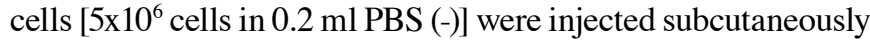
into five female SCID mice (CB-17 SCID; Okayama University Animal Research Laboratory, Okayama, Japan). The progress of the xenografts was monitored two times a week for 3 months.

Multiplex quantitative real-time PCR $(Q-P C R)$ for $M C P y V$ detection. Multiplex Q-PCR was performed as previously described $(4,19)$.

\section{Results}

Histology and immunohistochemistry of the original $\mathrm{LCH}$ lesion. Histological examination of hematoxylin and eosin (H\&E)-stained sections (Fig. 1A-D) and immunohistochemistry of the initial LCH bone lesion showed the presence of CD1a-positive (Fig. 1E and F) and S100-positive cells (Fig. 1J and L). Cytokeratin (AE1/3)-positive cells with kidney-like nuclei were distributed across the LCH lesion (Fig. 1H, I and $\mathrm{K}$ ). Double staining for $\mathrm{S} 100$ and AE1/3 showed the presence of four types of immunoreactive cells within the lesion: S100/AE1/3; S100 ${ }^{+} / \mathrm{AE} 1 / 3^{-}$(green in Fig. $1 \mathrm{~J}$ and L); 

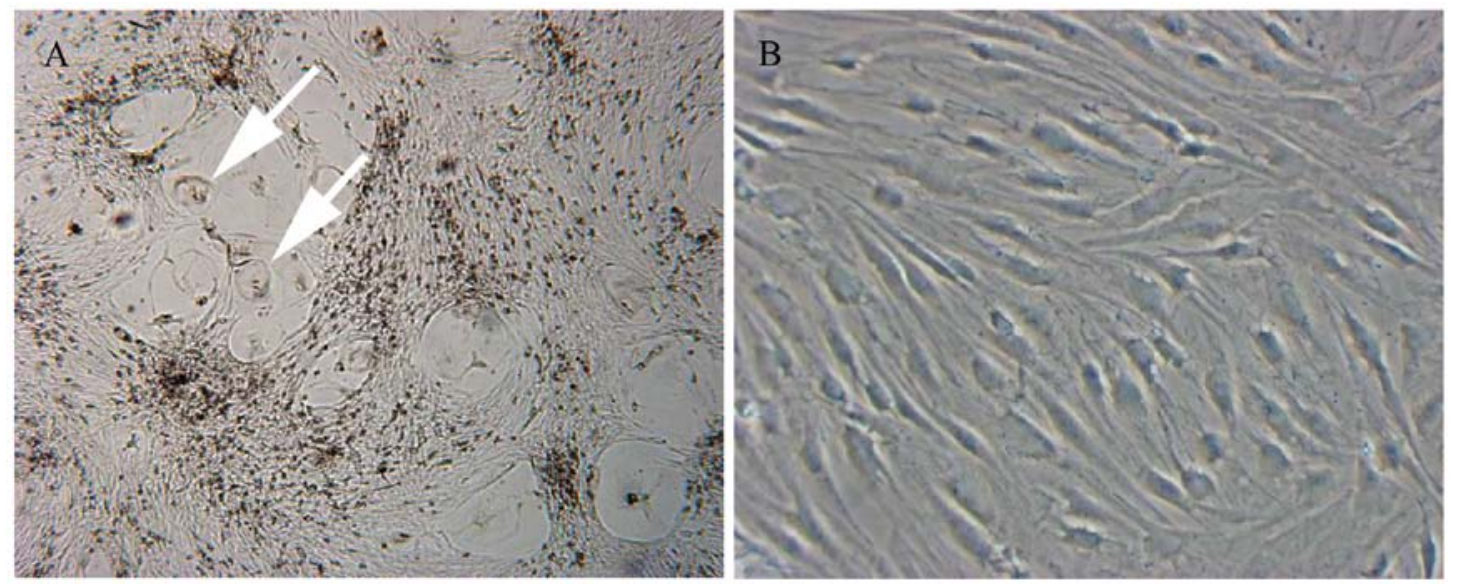

Figure 2. Inverted phase-contrast microscopic appearance of a primary culture of an LCH lesion and the PRU-1 cell line. (A) Primary culture cells derived from the LCH lesion showing spindle-shaped cells admixed with giant cells (arrows) (magnification, $\mathrm{x} 4$ ). (B) PRU-1 cells showing spindle or stellate morphology (magnification, $\mathrm{x} 40$ ).

S100 $/ \mathrm{AE} 1 / 3^{+}$(red in Fig. 1K and L); and $\mathrm{S} 100^{+} / \mathrm{AE} 1 / 3^{+}$(orange in Fig. 1L). Within the peripheral stromal component of the lesion, scattered spindle- or stellate-shaped $\mathrm{FXIIIa}^{+}$cells (Fig. 1G) and a low number of $\mathrm{CD}^{+} \mathrm{a}^{+}$cells harboring foci (arrowhead) were observed (Fig. 1E).

Establishment of the PRU-1 cell line. Primary cultures obtained after seeding the isolated cells from the LCH infiltrate contained mixed adherent cell populations of variable size and morphology (Fig. 2A). During the second in vitro passage, adherent spindle-shaped cells grew predominantly. One month after initial plating, the proliferating cells could be maintained in DMEM supplemented with $10 \%$ fetal calf serum, L-glutamine and antibiotics. After 6 weeks of continuous culture, densely packed adherent cells were further passaged at a density of $2 \times 10^{5}$ cells $/ \mathrm{ml}$. The cells continued to grow stably for at least 50 passages. This new cell line, was named PRU-1 (Fig. 2B) and was extensively characterized.

Flow cytometry. The analysis of PRU-1 from the early seventh passage showed that the predominantly expressed molecules were CD14, HLA-ABC, CD58 (leukocyte-function associated molecule-3) and E-cadherin (Fig. 3). LC markers such as CD1a, CD207 (langerin) and CD209 (DC sign; immature DC marker) were negative. CD83 (B cell activation protein; DC marker), CD11b, CD86 [CD152 (CTLA4) ligand; interdigitating cell marker] and CD34 were negative.

Immunophenotype of $P R U-1$ and a special reaction for glycogen. The immunocytochemical profiles of PRU-1 cells are summarized in Table I. Application of a large panel of antibodies demonstrated that the PRU-1 cells were immunoreactive to CD11c (Fig. 4A), FXIIIa (Fig. 4B), CD43, CD54 (ICAM-1), CD56 (NCAM), CD99 (MIC2), CD106 ( $\alpha \mathrm{VCAM}-1$ ), and CD141 (thrombomodulin), but not to CD1a, CD10, S100, CD14 and CD34 (Fig. 4C). In addition, AE1/3 keratin (Fig. 4D), vimentin, $\alpha$-smooth muscle actin and muscle actin were expressed. Cytocentrifuge smears of the PRU-1 cells showed the presence of glycogen, as indicated by the positive PAS reaction and confirmed by the diastase PAS reaction.
Analysis of TCR $\gamma$ in the LCH lesion and PRU-1 cells by PCR. Since TCR $\gamma$ expansion has been reported in LCH lesions occurring in patients treated for T-lymphoblastic leukemia/ lymphoma (20), we determined the TCR $\gamma$ gene status in both the LCH original tissue and the PRU-1 cells by PCR. GeneMapper $^{\mathrm{TM}}$ retrieved only polyclonal bands using the amplified DNA. However, histological analysis of the lesion showed that numerous $\mathrm{T}$ cells intermingled with $\mathrm{LC}$ cells. No rearrangement of the TCR $\gamma$ band was detected in the PRU-1 cells.

$E M$. Various organelles such as the mitochondria, rough ER, Golgi apparatus, and lysosomes were observed in the PRU-1 cells by EM. No Birbeck granules were detected.

Cytogenetic analysis. Repeated karyotype analysis of seven metaphases was performed, which showed male karyotypes consisting of the following constitutions: one metaphase spread showing 39,XY,-2,-4,-8,-12,-12,-14, add(18)(q21),20,+mar, one metaphase spread showing 44,XY,-11,-14,add(18)(q21) (Fig. 5), one metaphase spread showing $44, \mathrm{XY},-10,-14$, and four metaphase spreads showing $46, \mathrm{XY}$. The $18 \mathrm{q} 21$ abnormality was detected two times.

Effects of the PRU-1 conditioned medium on the biology and phenotype of lymphocytes and monocytes from a healthy donor. Lymphocytes and monocytes were co-cultured in the PRU-1 conditioned medium. After 7 days of culture in the conditioned medium, the monocytes underwent a change in morphology, resulting in spindle-shaped cells (Fig. 6A and $\mathrm{B}$ ), whereas some monocytes acquired CD1a positivity (Fig. 6C and D). Lymphocytes cultured in the PRU-1 supernatant showed a higher proliferation rate than the control lymphocytes cultured in a conditioned medium from $\mathrm{HeLa}$ cell culture.

Growth in SCID mice. To evaluate whether PRU-1 possessed normal or neoplastic characteristics, we examined the tumorigenicity of the PRU-1 cell line. No tumor growth was detected in the five female SCID mice that were monitored for 3 months. 

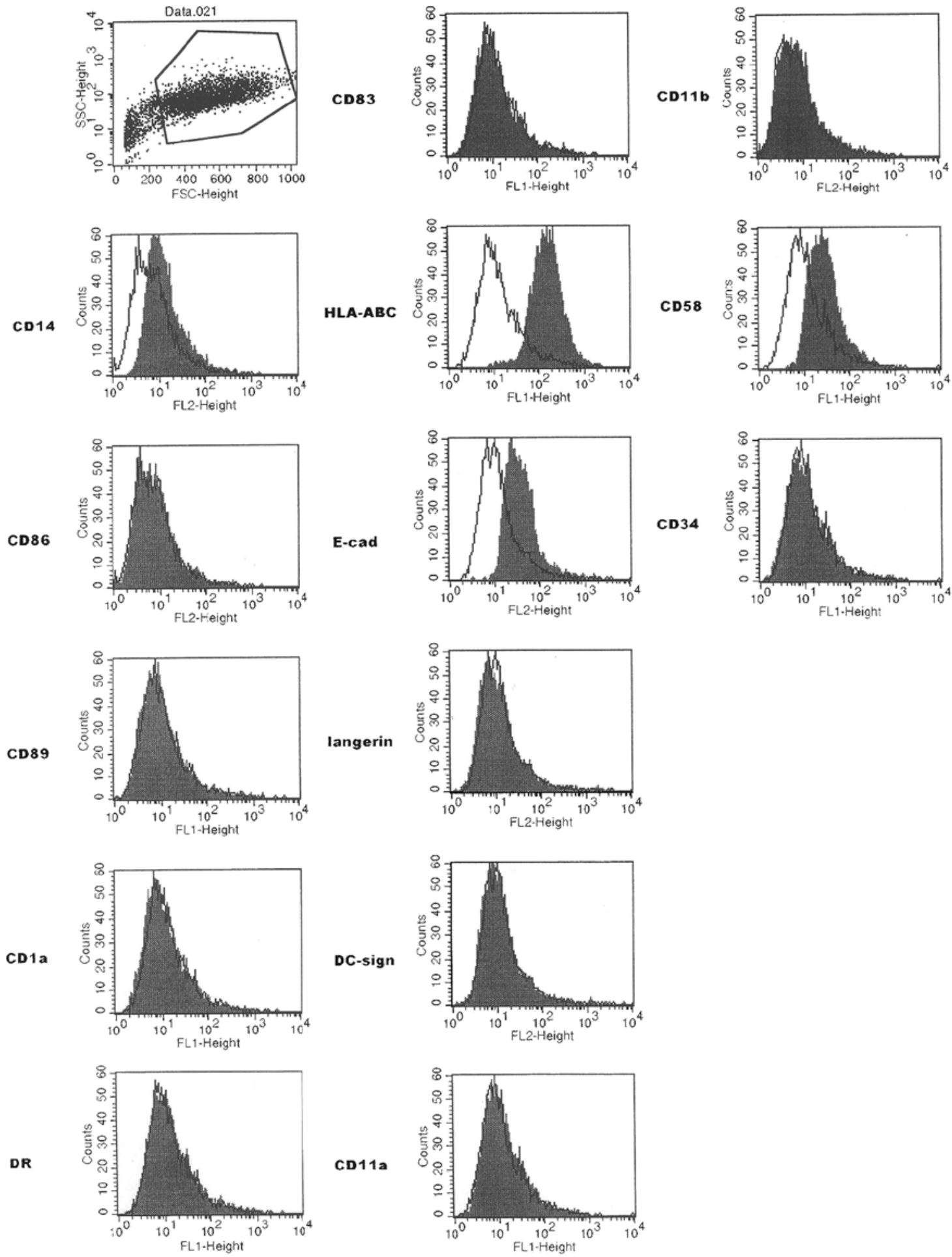

Figure 3. Flow cytometric analyses of the early seventh passage of PRU-1 cells. The expression of HLA-ABC, CD58, CD14 and E-cadherin was observed. No expression of Langerhans cell characteristic markers such as CD1a, langerin and DC sign was observed. CD83, CD86, CD89, CD11a and CD11b were not expressed.

$Q$-PCR for MCPyV.No MCPyV DNA sequences were detected in the PRU-1 cell line.

\section{Discussion}

Although several studies have established cell lines from LCH lesions, it is generally difficult to retain its full LC characteristics (17,21-23). Previous studies have shown success in short-term culture of LCH tissues; however, these only allowed analyses of cell morphology (24), cytokine production (IL-1 and PGE2) (22), and cell differentiation capacities (23). A few subsequent passages have been achieved, whereas most studies have suggested that $\mathrm{LCH}$ cells might have a limited life span in vitro. In the present study, a long-term growing cell line was obtained, which in turn gave rise to the question of whether the PRU-1 cell line was related to the LC lineage or represented an 

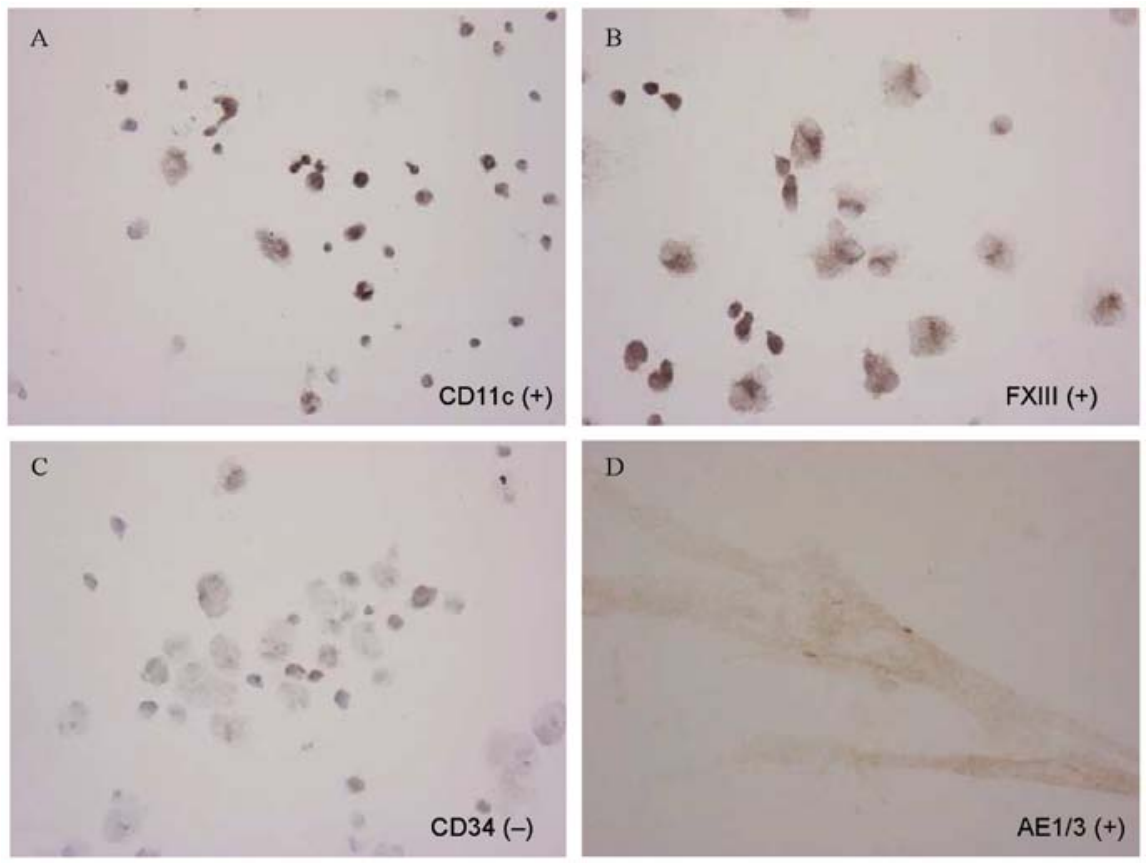

Figure 4. Immunohistochemical analysis of PRU-1 cells prepared using cytospin (A-C) or cultured in a Labtek chamber (D). (A) CD11c-positive cells (magnification, x20). (B) FXIIIa-positive cells (magnification, x20). (C) CD34-postive cells (magnification, x20). (D) AE1/3-positive cells cultured in a Labtek chamber (magnification, $\mathrm{x} 40$ ).

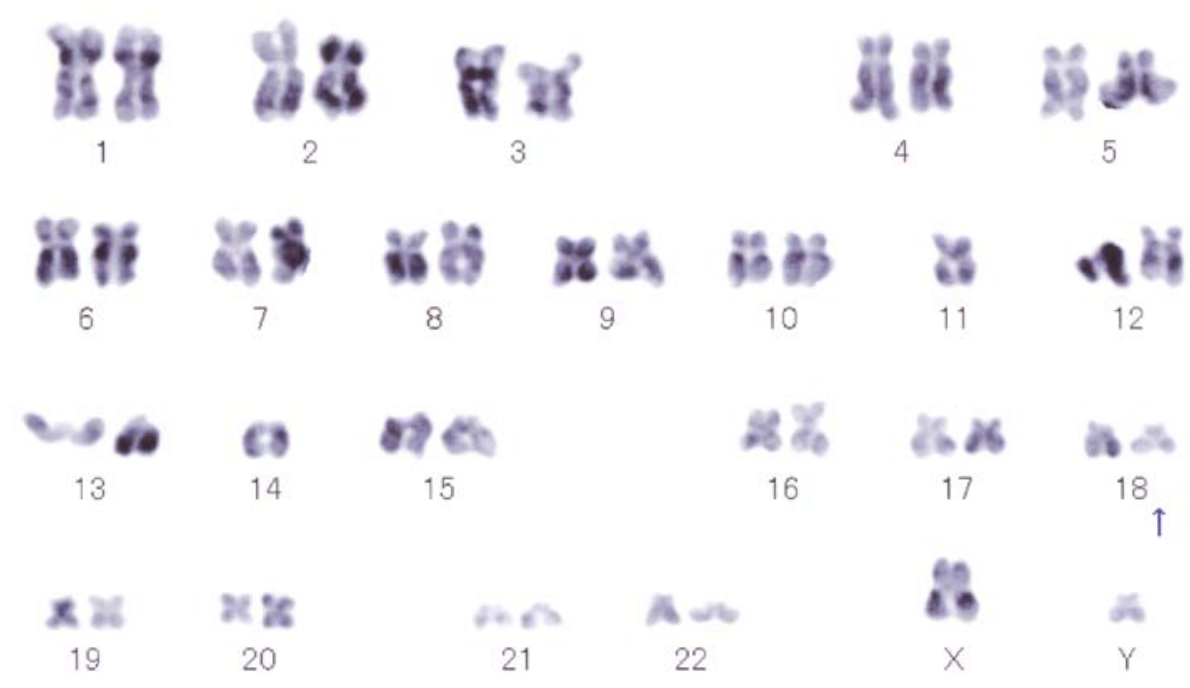

Figure 5. Cytogenetic analysis of PRU-1 cells. Metaphase showing 44,XY,-11,-14,add(18)(q21). Add(18)(q21) was detected two times (arrow).

LC progenitor. LC progenitors are components of multipotent bone marrow-derived stromal cellular compartments that have been implicated in self-perpetuating granulomatous lesions. Thus, the immunocytochemical profile, namely the FXIIIa positivity and the absence of CD34 expression and distinct cytoplasmic Birbeck granules, were $a$ priori consistent with a DDC origin for the PRU-1 cells. It was previously reported that CD1a-positive DCs from peripheral blood mononuclear cells could differentiate into any of the three cell types: histiocyte DC-like cells $\left(\mathrm{FXIIIa}^{+++}\right)$, fibroblast-like cells $\left(\mathrm{FXIIIa}^{++}\right)$, and giant cell-like cells $\left(\mathrm{FXIIIa}^{+}\right)$(25). In fact, fibroblast-like $\mathrm{FXIIIa}^{+}$DDC is the cell type that typically proliferates in dermatofibromas. In this regard, PRU-1 exhibited phenotypic characteristics of fibroblast-like DDCs in terms of FXIIIa positivity and its spindle-shaped cellular morphology. In addition, EM analysis showed that PRU-1 harbored numerous organelles. Similarly, dermatofibroma tumoral cells show well-developed rough ER, conspicuous Golgi apparatus, and a variable number of mitochondria (26). These features thus suggested that PRU-1 might be a clonal expansion derived from $\mathrm{FXIIIa}^{+}$stellate cells present in the fibrous area of the original lesion.

The PRU-1 cells also expressed cytokeratin (AE1/3= cytokeratin 1-8/10/14/15/16/19) (Table I). The original LCH lesions systematically showed scattered keratin-positive cells (Fig. 1H-L). Double staining indicated that the $\mathrm{LCH}$ lesion contained a mixture of $\mathrm{S} 100^{+} / \mathrm{AE} 1 / 3^{+}, \mathrm{S} 100^{+} / \mathrm{AE} 1 / 3^{-}$, $\mathrm{S} 100^{-} / \mathrm{AE} 1 / 3^{+}$and S100\%/AE1/3 cells. Bone LCH has a self- 


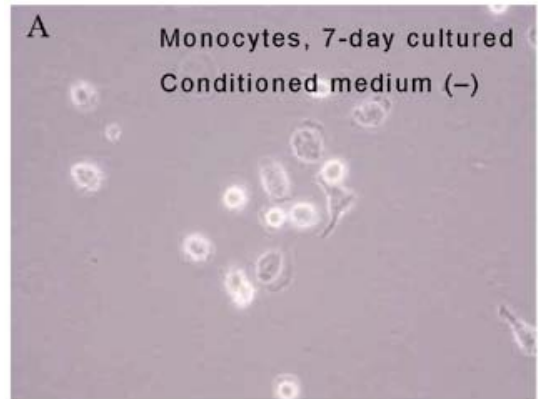

C

Monocytes, 7-day cultured Conditioned medium (-)

CD1a-negative monocytes

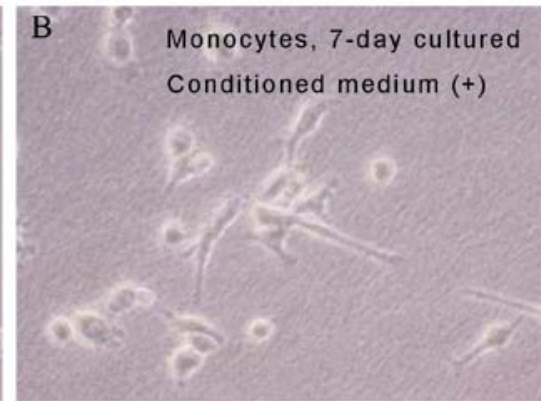

D Monocytes, 7-day cultured Conditioned medium (+)

CD1a-positive cells surrounded by $C D 1 a-n e g a t i v e$ monocytes

Figure 6. The shape and CD1a reactivity of monocytes from a healthy donor in primary culture changed after 1 week of culture in the supernatant (conditioned medium) from PRU-1 culture. (A) Monocytes cultured without PRU-1 conditioned medium for 7 days. Phase-contrast microscopy. (B) Monocytes cultured in PRU-1 conditioned medium for 7 days. Phase-contrast microscopy. (C) Monocytes cultured without PRU-1 conditioned medium for 7 days showed negative CD1a immunostaining. (D) Monocytes cultured in PRU-1 conditioned medium for 7 days, some of which showed the appearance of CD1a-positive LCH cells among CD1a-negative cells. Immunostain.

limiting tendency and develops into scar-like granuloma with the accumulation of a mixture of foamy cells and macrophages (27). One of the important questions that needs to be answered is the origin of $\mathrm{LCH}$ cells. The presence of $\mathrm{S} 100^{+} / \mathrm{AE} 1 / 3^{+}$cells raises the question of whether the AE1/3+ cells originate from typical LCH cells or from other cell types that comprise the $\mathrm{LCH}$ lesion. Keratin is present in the cellular cytoskeleton, and cytokeratin ${ }^{+}$cells could produce cytokine (28) with admixed cells in the LCH lesion (29). PRU-1 phenotypically consisted of $\mathrm{S} 100^{-}, \mathrm{AE} 1 / 3^{+}$and $\mathrm{FXIIIa}^{+}$ cells. Moreover, scattered FXIIIa ${ }^{+}$cells were detected in the peripheral fibrous area of the original LCH lesion (Fig. 1G). In general, it is accepted that LC is derived from an LC precursor through an immature cell type and that LC can differentiate into interdigitating cells through veiled cells (30). Similarly, DDCs seem to have been derived from a cellular precursor that has differentiated into DCs or LCs. There are data indicating that LCs are incapable of differentiating into the DDC type (31). We think PRU-1 was derived from stromal cell types that comprised the $\mathrm{LCH}$ lesion.

It has been suggested that some LCH cells are derived from the T cell lineage with TCR $\gamma$ monoclonality (20), although a diverse collection of data exists. Our PCR results allowed the characterization of the polyclonal TCR $\gamma$ genomic structure of the PRU-1 original tissue, as well as indicated the absence of TCR $\gamma$ monoclonality in the PRU-1 cells. These data showed the presence of polyclonal T cells in the $\mathrm{LCH}$ original tissue and that PRU-1 elements did not originate from the $\mathrm{T}$ cell lineage.

Cytogenetic analyses of PRU-1 showed the presence of an $18 \mathrm{q} 21$ chromosomal abnormality. We recently described the possibility of a causal relationship between MCPyV and LCH (4) and Scappaticci et al (16) found that peripheral blood lymphocytes from LCH patients contained chromosomal abnormality and pointed out that $\mathrm{LCH}$ was caused by environmental viral agents. The $18 \mathrm{q} 21$ abnormality which was detected two times may also indicate a clonal proliferation of PRU-1 cells and the effect of viral infection as shown in blood lymphocytes by Scappaticci et al (16). In this context, chromosomal rearrangements have been detected in a few $\mathrm{LCH}$ cases $(32,33)$, as well as in pulmonary $\mathrm{LCH}$ which is thought to be a reactive and neoplastic disorder caused by cigarette smoking $(2,7)$. Familial clustering suggesting a genetic event in $\mathrm{LCH}$ has also been reported (6,34-36).

To assess cytokine production, the conditioned medium was added to the monocyte and lymphocyte cultures (37) as well as to lymphocytes or monocytes from a healthy donor. Observed phenotypic changes included some CD1a- monocytes transforming into $\mathrm{CD}^{+} \mathrm{a}^{+}$cells and a high proliferation rate compared with that of the control. These findings suggest that the PRU-1 cultured cells produced stimulatory growth or differentiation factors that have yet to be fully characterized.

Analysis of specific chromosomal aberrations using the PRU-1 in vitro model and conditioned medium might also provide new insights on $\mathrm{LCH}$ pathogenesis, i.e. LCH microenvironment contributed by stromal cells.

We recently described the relationship between MCPyV and $\mathrm{LCH}$ (4) and hypothesized that $\mathrm{LCH}$ was a reactive disorder with an underlying oncogenic potential. Extinction of stimuli such as MCPyV infection could cause spontaneous healing of $\mathrm{LCH}$, although MCPyV has been considered as a potential neoplastic agent for Merkel cell carcinoma (38). However, in the PRU-1 cells, MCPyV DNA was not detected and was not likely to contribute to the cell line establishment, although the genomic instability of PRU-1 cells might be induced by MCPyV infection (16). 
Finally, the LCH lesion is a mixture of various cells, including LC-like cells, DDC-like cells, macrophages, lymphocytes, neutrophils, lymphocytes and eosinophils. We were successful in establishing a $\mathrm{CK}^{+} / \mathrm{S} 100^{-}$cell line, PRU-1, from a bone $\mathrm{LCH}$ lesion that retains DDC-like characteristics such as CD11c, CD54 and CD141 immunoreactivity, in addition to FXIIIa expression. The PRU-1 conditioned medium may contain yet unknown specific molecules that may contribute to the formation of LCH lesions, as well as facilitate in induction studies using $\mathrm{CD}_{1} \mathrm{a}^{+}$or $\mathrm{LCH}$ cells.

\section{Acknowledgements}

The authors are indebted to Ms. Masumi Furutani (Central Laboratory, Okayama University) for her help in performing EM analysis.

\section{References}

1. Writing Group of the Histiocyte Society: Histiocytosis syndromes in children. Writing Group of the Histiocyte Society. Lancet 1: 208-209, 1987.

2. Yousem SA, Dacic S, Nikiforov YE and Nikiforova M: Pulmonary Langerhans cell histiocytosis: profiling of multifocal tumors using next-generation sequencing identifies concordant occurrence of BRAF V600E mutations. Chest 143: 1679-1684, 2013.

3. Badalian-Very G, Vergilio JA, Degar BA, et al: Recurrent BRAF mutations in Langerhans cell histiocytosis. Blood 116: 1919-1923, 2010.

4. Murakami I, Matsushita M, Iwasaki T, et al: Merkel cell polyomavirus DNA sequences in peripheral blood and tissues from patients with Langerhans cell histiocytosis. Hum Pathol 45: 119-126, 2014.

5. Sakata N, Toguchi N, Kimura M, Nakayama M, Kawa K and Takemura T: Development of Langerhans cell histiocytosis associated with chronic active Epstein-Barr virus infection. Pediatr Blood Cancer 50: 924-927, 2008.

6. Chen CJ, Ho TY, Lu JJ, et al: Identical twin brothers concordant for Langerhans' cell histiocytosis and discordant for Epstein-Barr virus-associated haemophagocytic syndrome. Eur J Pediatr 163: 536-539, 2004

7. Yousem SA, Colby TV, Chen YY, Chen WG and Weiss LM: Pulmonary Langerhans' cell histiocytosis: molecular analysis of clonality. Am J Surg Pathol 25: 630-636, 2001.

8. Tazi A, Hiltermann JN and Vassallo R: Adult lung histiocytosis. In: Histiocytic Disorders of Children and Adults. Weitzman S and Egeler RM (eds.). Cambridge University Press, Cambridge, pp187-207, 2005.

9. Corbeel L, Eggermont E, Desmyter J, et al: Spontaneous healing of Langerhans cell histiocytosis (histiocytosis X). Eur J Pediatr 148: 32-33, 1988

10. Mogulkoc N, Veral A, Bishop PW, Bayindir U, Pickering CA and Egan JJ: Pulmonary Langerhans' cell histiocytosis: radiologic resolution following smoking cessation. Chest 115: 1452-1455, 1999.

11. Von Essen S, West W, Sitorius M and Rennard SI: Complete resolution of roentgenographic changes in a patient with pulmonary histiocytosis X. Chest 98: 765-767, 1990.

12. Kawakubo Y, Kishimoto H, Sato Y, et al: Human cytomegalovirus infection in foci of Langerhans cell histiocytosis. Virchows Arch 434: 109-115, 1999.

13. Leahy MA, Krejci SM, Friednash M, et al: Human herpesvirus 6 is present in lesions of Langerhans cell histiocytosis. J Invest Dermatol 101: 642-645, 1993.

14. Glotzbecker MP, Carpentieri DF and Dormans JP: Langerhans cell histiocytosis: a primary viral infection of bone? Human herpes virus 6 latent protein detected in lymphocytes from tissue of children. J Pediatr Orthop 24: 123-129, 2004.

15. Jenson HB, McClain KL, Leach CT, Deng JH and Gao SJ Evaluation of human herpesvirus type 8 infection in childhood langerhans cell histiocytosis. Am J Hematol 64: 237-241, 2000.

16. Scappaticci S, Danesino C, Rossi E, et al: Cytogenetic abnormalities in PHA-stimulated lymphocytes from patients with Langerhans cell histocytosis. AIEOP-Istiocitosi Group. Br J Haematol 111: 258-262, 2000.
17. Gogusev J, Telvi L, Murakami I, et al: DOR-1, A novel CD10 stromal cell line derived from progressive Langerhans cell histiocytosis of bone. Pediatr Blood Cancer 44: 128-137, 2005.

18. Van Dongen JJ, Langerak AW, Bruggemann M, et al: Design and standardization of PCR primers and protocols for detection of clonal immunoglobulin and T-cell receptor gene recombinations in suspect lymphoproliferations: report of the BIOMED-2 Concerted Action BMH4-CT98-3936. Leukemia 17: 2257-2317, 2003.

19. Kuwamoto S, Higaki H, Kanai K, et al: Association of Merkel cell polyomavirus infection with morphologic differences in Merkel cell carcinoma. Hum Pathol 42: 632-640, 2011.

20. Feldman AL, Berthold F, Arceci RJ, et al: Clonal relationship between precursor T-lymphoblastic leukaemia/lymphoma and Langerhans-cell histiocytosis. Lancet Oncol 6: 435-437, 2005.

21. Nezelof $\mathrm{C}$ and Basset F: An hypothesis Langerhans cell histiocytosis: the failure of the immune system to switch from an innate to an adaptive mode. Pediatr Blood Cancer 42: 398-400, 2004.

22. Arenzana-Seisdedos F, Barbey S, Virelizier JL, Kornprobst M and Nezelof C: Histiocytosis X. Purified $\left(\mathrm{T}^{+}\right)$cells from bone granuloma produce interleukin 1 and prostaglandin E2 in culture. J Clin Invest 77: 326-329, 1986.

23. Geissmann F, Lepelletier Y, Fraitag S, et al: Differentiation of Langerhans cells in Langerhans cell histiocytosis. Blood 97: 1241-1248, 2001

24. Nezelof $\mathrm{C}$ and Basset F: Langerhans cell histiocytosis research. Past, present, and future. Hematol Oncol Clin North Am 12: 385-406, 1998.

25. Aiba $\mathrm{S}$ and Tagami H: Phorbol 12-myristate 13-acetate can transform monocyte-derived dendritic cells to different cell types similar to those found in dermatofibroma. A possible in vitro model of the histogenesis of dermatofibroma. J Cutan Pathol 25: 65-71, 1998.

26. Erlandson RA: Ultrastructural features of specific human neoplasms with clinicopathologic, immunohistochemical, and cytogenetic correlations. In: Diagnostic Transmission Electron Microscopy of Tumors. Raven Press, New York, NY, pp243-832, 1994.

27. Weitzman S and Egeler RM: Langerhans cell histiocytosis of bone. In: Histiocytic Disorders of Children and Adults. Cambridge University Press, Cambridge, pp154-173, 2005.

28. Lu H, Chen J, Planko L, Zigrino P, Klein-Hitpass L and Magin TM: Induction of inflammatory cytokines by a keratin mutation and their repression by a small molecule in a mouse model for EBS. J Invest Dermatol 127: 2781-2789, 2007.

29. Egeler RM, Favara BE, van Meurs M, Laman JD and Claassen E: Differential in situ cytokine profiles of Langerhans-like cells and $\mathrm{T}$ cells in Langerhans cell histiocytosis: abundant expression of cytokines relevant to disease and treatment. Blood 94: 4195-4201, 1999.

30. Raushenbakh MO, Ivanova VD, Shevchenko VE, Makhonova LA and Sergeev AV: Congenital tyrosine metabolism disorders in children with hemoblastoses. Vestn Akad Med Nauk SSSR: 19-24, 1981 (In Russian).

31. Larrengina AT and Falo LD Jr: Dendritic cells in the context of skin immunity. In: Dendritic Cells. Lotze MT and Thomson AW (eds.). Academic Press, San Diego, CA, pp301-314, 2001.

32. Betts DR, Leibundgut KE, Feldges A, Pluss HJ and Niggli FK: Cytogenetic abnormalities in Langerhans cell histiocytosis. Br J Cancer 77: 552-555, 1998.

33. Murakami I, Gogusev J, Fournet JC, Glorion C and Jaubert F: Detection of molecular cytogenetic aberrations in langerhans cell histiocytosis of bone. Hum Pathol 33: 555-560, 2002.

34. Arico M, Nichols K, Whitlock JA, et al: Familial clustering of Langerhans cell histiocytosis. Br J Haematol 107: 883-888, 1999.

35. Dufour C, Lanciotti M, Micalizzi C, Valetto A and Haupt R: Non-identical twin sisters concordant for Langerhans cell histiocytosis and discordant for secondary acute promyelocytic leukemia. Med Pediatr Oncol 37: 70-72, 2001.

36. Enjolras O, Leibowitch M, Bonacini F, Vacher-Lavenu MC and Escande JP: Congenital cutaneous Langerhans histiocytosis. Apropos of 7 cases. Ann Dermatol Venereol 119: 111-117, 1992 (In French).

37. Miyatani K, Takahashi K, Yanai H, Yoshino T and Akagi T: Partial purification and characterization of dendritic cell differentiation factor. Acta Med Okayama 48: 67-72, 1994.

38. Feng H, Shuda M, Chang Y and Moore PS: Clonal integration of a polyomavirus in human Merkel cell carcinoma. Science 319: 1096-1100, 2008. 